\title{
A Novel Fifteen Level Inverter for Photovoltaic Power Supply System
}

\author{
Abdul Rahiman Beig ${ }^{1}$ \\ Dept. of Electrical and Electronics \\ Engineering \\ National Institute of Technology \\ Suratkal, INDIA \\ arbeig@ieee.org
}

\author{
Udaya Kumar R.Y. \\ Dept. of Electrical and Electronics \\ Engineering \\ National Institute of Technology \\ Suratkal, INDIA \\ udaya@nitk.ac.in
}

\author{
V.T.Ranganathan \\ Dept. of Electrical Engineering \\ Indian Institute of Science \\ Bangalore-12, INDIA \\ vtran@ee.iisc.ernet.in
}

\begin{abstract}
A novel de to ac inverter for photovoltaic power supply system is presented in this paper. The objective is to develop a low cost, reliable and efficient photovoltaic power supply unit for domestic applications. A fifteen level cascaded $\mathbf{H}-$ Bridge configuration using low voltage MOSFETs as switching devices is used. This configuration results in sinusoidal output voltages with step modulation and fundamental frequency switching. The proposed configuration has reduced conduction loss and switching loss. Simple gate drive circuit is designed using commonly available integrated circuit components. The simulation results are presented.
\end{abstract}

Keywords: Multilevel inverter; Photovoltaic power supply; Cascaded H- Bridge.

\section{INTRODUCTION}

In developing countries and under developed countries, there is severe shortage of electrical energy. Because of the large gap between the demand and supply, the electric utilities will resort to frequent load shedding. Apart from this, sometimes it is not possible to take electric grid to remote areas because of the environmental and economical reasons. Under such conditions electrical energy can be generated from the alternative energy sources. One such alternative source of electric energy is solar energy.

Photovoltaic cells generate electric energy from the solar energy. Although solar energy is available abundantly and free of cost, the cost of the photovoltaic cells is very high. Hence the initial investment on solar energy will be very high. The electrical energy form the solar cells is dc form and it has to be stored and processed to required form to suite the load requirements.

Fig. 1 shows the general arrangement used in photovoltaic standby power supply units. AC to de inverter circuits are employed to convert the dc voltage to ac voltage of required frequency and voltage. Fundamentally there are two approaches; one is to connect the cells in series to generate high voltage dc and use high voltage dc to ac inverter circuit. This configuration requires devices of higher voltage rating for the inverter. Another approach is to use low voltage power devices for the inverter and step up the voltage using transformers. In both the cases high switching frequency is employed to generate sinusoidal output voltage and to reduce

${ }^{1}$ Currently Research Student at Dept. of Electrical Engineering,

Indian Institute of Science Bangalore -12, INDIA

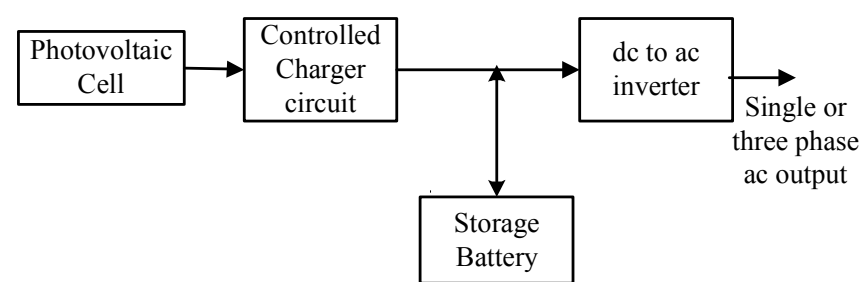

Figure 1. Functional block diagram of photovoltaic power supply unit

filter requirements. High switching frequency will result in increased switching losses and EMI problems, which in turn calls for the proper design of heat sinks and layout of the power circuit. In order to reduce the switching losses, resonant converters can be used, but the design of these resonant type inverters is complicated and costly.

Multilevel inverters can synthesize higher voltages using devices of lower voltage rating. An $N$ - level inverter output phase voltage will have $N$ levels. The wave shape and hence the THD of the output voltage improves as the number of levels increase. Multi level inverters can be used as an alternative configuration for the $\mathrm{dc}$ to ac inverter in photovoltaic applications. Diode clamp inverter, cascaded Hbridge inverter and flying capacitor type inverter are the three widely used configurations of multilevel inverters [1]. Cascaded $\mathrm{H}$-bridge inverter power circuit is simple and uses least number power circuit components among these three configurations. Also cascaded $\mathrm{H}$-bridge is ideally suited for systems such as photovoltaic where isolated input dc source is available [1][2].

In this paper a fifteen level multilevel inverter using cascaded $\mathrm{H}$ - Bridge inverters is employed as dc to ac inverter for photovoltaic power supply system. The working principles of this inverter are explained in section II. Fifteen level inverter results in sinusoidal output voltage and current, hence there is no need of filter circuits. Since the output voltage is compatible with the load, there is no need of output transformer. Seven HBridge circuits are connected in cascade. The voltage across each of the device is $1 / 7^{\text {th }}$ of the peak output voltage. Hence low voltage MOSFETs are employed. The low voltage MOSFETs have low on state resistance $\left(R_{d s(o n)}\right)$, hence the conduction losses are reduced. Step modulation is employed in the proposed inverter, which results in low switching losses. The simulation results are presented. The experimental 
implementation of the system is under progress and some aspects of the experimental implementation are given in section IV.

\section{CASCADED H-BRIDGE INVERTER}

\section{A. Working Principle}

Fig. 2 shows the single cell of multilevel-cascaded $\mathrm{H}$ bridge configuration. The output of this cell will have three levels namely $+V, 0$ and $-V$. The switch position and the output voltage and the state of the H-Bridge are given in table I. Using one single H-Bridge, a three level inverter can be realized. These $\mathrm{H}$-Bridge cells can be connected in cascade to obtain multilevel-cascaded H-Bridge inverter. The power circuit of five level cascaded H-bridge inverter is shown in fig.3. If $V$ is the dc volt age of each $\mathrm{H}$-bridge cell, then a five level inverter phase voltage will have five levels namely $+2 \mathrm{~V}$, $+V, 0,-V$ and $-2 V$. Similarly seven level inverter will have $+3 V,+2 V,+V, 0,-V,-2 V$ and $-3 V$. A five-level cascaded $\mathrm{H}-$ Bridge inverter requires two $\mathrm{H}$-Bridges. A seven-level cascaded $\mathrm{H}$-Bridge inverter requires three $\mathrm{H}$-Bridges. In general a $N$-level inverter requires $(N-1) / 2 \mathrm{H}$-Bridge cells in each phase and phase voltage will have $N$ levels.

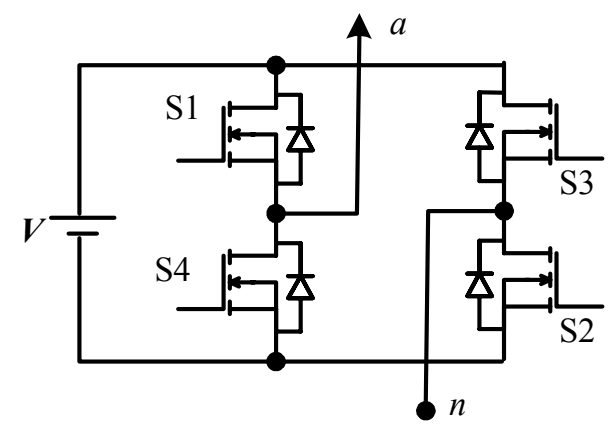

Figure 2. Power circuit of single H-Bridge cell

TABLE I. Switch Status AND State of H BRIDGE

\begin{tabular}{|c|c|c|}
\hline Switch status & $\begin{array}{c}\text { Output voltage } \\
\text { (Volts) }\end{array}$ & State \\
\hline S1 and S2 ON; S3 and S4 OFF & V & +1 \\
\hline $\begin{array}{c}\text { S1 and S3 ON; S2 and S4 OFF } \\
\text { OR }\end{array}$ & 0 & 0 \\
S2 and S4 ON; S1 and S3 OFF & - V & -1 \\
\hline S3 and S4 ON; S1 and S2 OFF & \\
\hline
\end{tabular}

\section{B. Features of Cascaded H-Bridge Inverter}

- Higher voltage levels can be synthesized using devices of low voltage rating. If $V$ is the dc voltage of each of the $\mathrm{H}$-Bridge cell, then each device will experience a off state voltage of $V$ volts and a $N$-level cascaded $\mathrm{H}$-Bridge can synthesize peak-to-peak voltage of $\left(N^{*} V\right)$ volts.

- $\quad$ Phase voltage of an $N$-level cascaded H-Bridge will have $N$ levels; hence wave shape will be improved and will result in improved $T H D$.

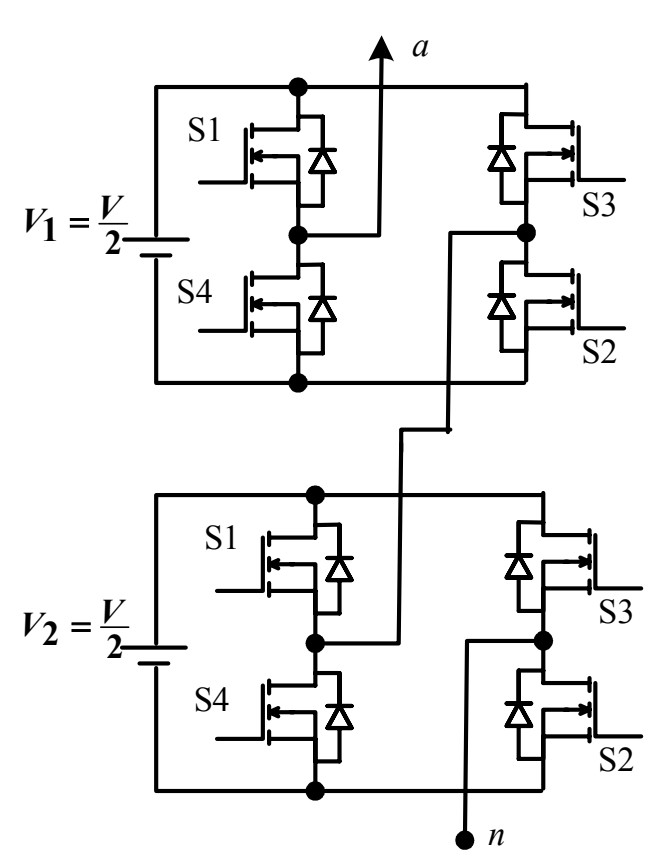

Figure 3. Power Circuit of five-level cascaded H-Bridge inverter

- Improved wave shape can be obtained even with fundamental frequency switching and step modulation. Low switching frequency will result in reduced switching loss in the devices. The switching angle of each cell can be selected to eliminate some of the lower order harmonics.

- In the above explanation, cascaded H-bridge will equal voltages are employed. However cells with different voltages can also be used. By proper selection of the voltage levels, some of the lower order harmonics can be eliminated.

- Modular structure makes the power circuit design simple and reliable. Under fault conditions, faulty cells can be bypassed and still the inverter will function with reduced output voltage levels. Since the cells are identical, faulty unit can be replaced quickly and downtime of the inverter can be reduced; hence high reliability can be achieved [3].

- $\quad$ Since the voltage across each cell is $V$ volt, low voltage MOSFETs with high current rating can be used. Low voltage rating MOSFETs will have low $\mathrm{R}_{D S(\text { on })}$, so the conduction loss will be low.

\section{Modulation Technique}

The conventional photovoltaic power supply systems use two level inverters. The two level inverters employ PWM technique and generally switched at high frequency to get improved output voltage waveform. High switching frequency will result in increased switching losses in the device and also give rise to EMI problems. Compared to two-level inverter, multilevel inverter can generate near sinusoidal output voltages 

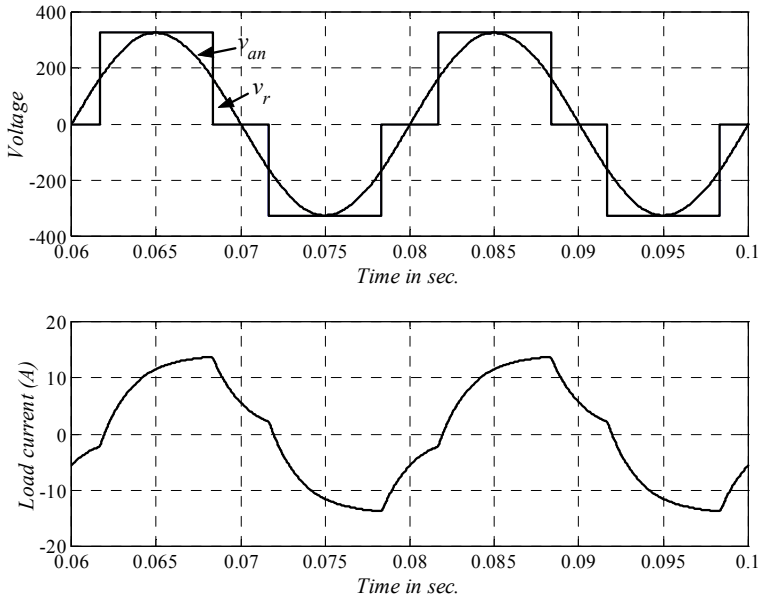

Figure 4. Output voltage and load current of the three-level cascaded HBridge inverter with step modulation and fundamental frequency switching
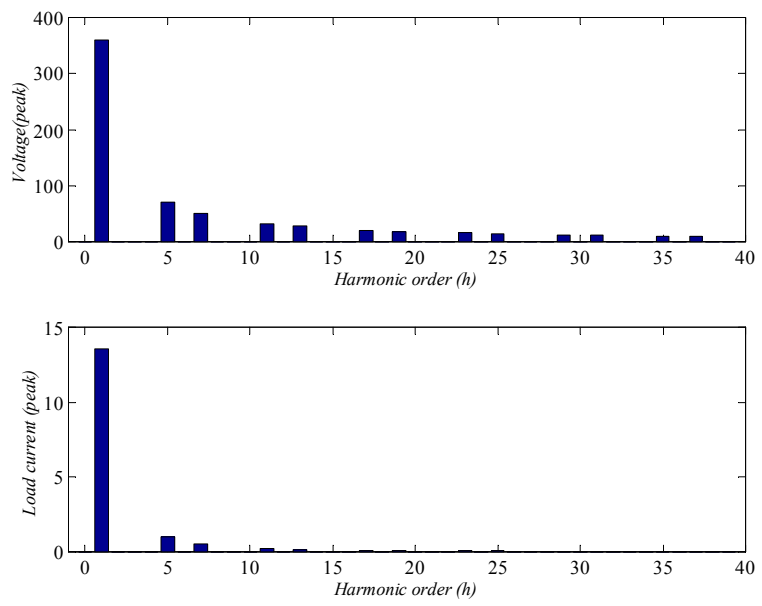

Figure 6. Three- level inverter: Harmonic spectra of phase voltage and load current with step modulation and fundamental frequency switching
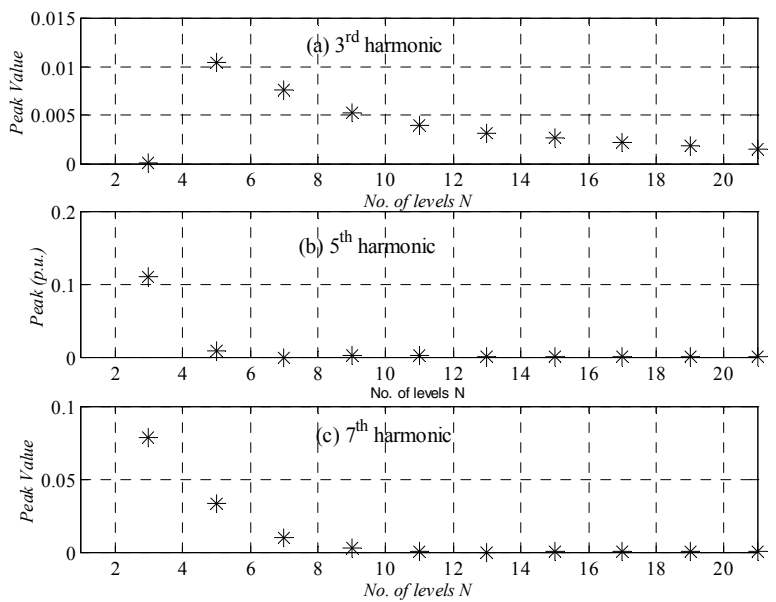
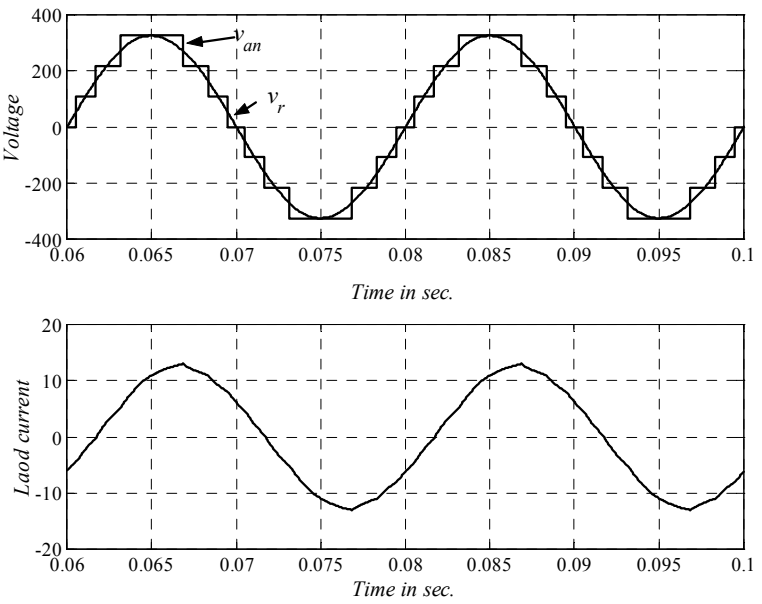

Figure 5. Output voltage and load current of the seven-level cascaded HBridge inverter with step modulation and fundamental frequency switching
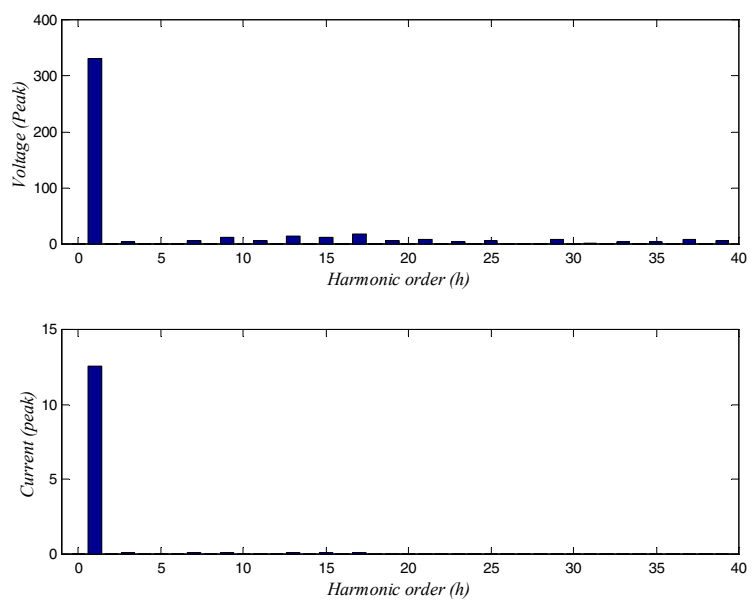

Figure 7. Seven- level inverter: Harmonic spectra of phase voltage and load current with step modulation and fundamental frequency switching
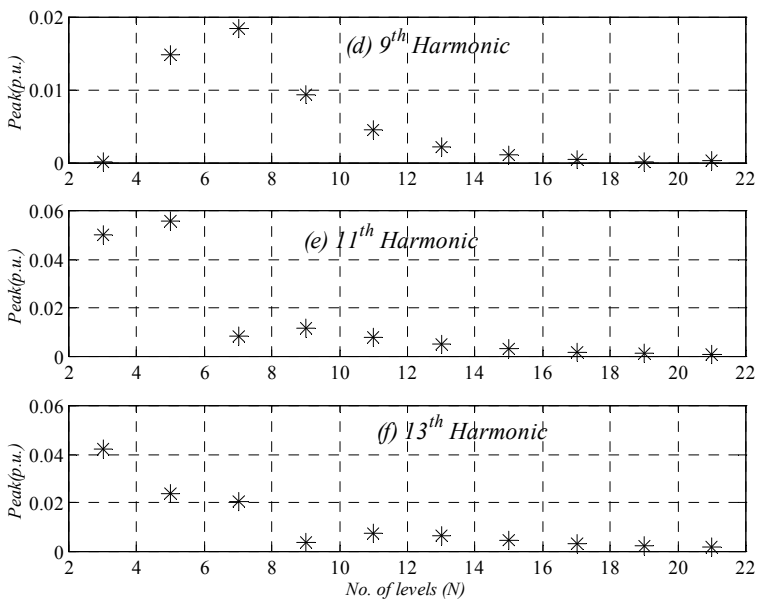

Figure 8. Variation of lower order harmonics $\left(3^{\text {rd }}, 5^{\text {th }}, 7^{\text {th }}, 9^{\text {th }}, 11^{\text {th }}\right.$ and $\left.13^{\text {th }}\right)$ with respect to $N(1$ pu. $=326 \mathrm{~V})$

IAS 2004

1167

0-7803-8486-5/04/\$20.00 @ 2004 IEEE 

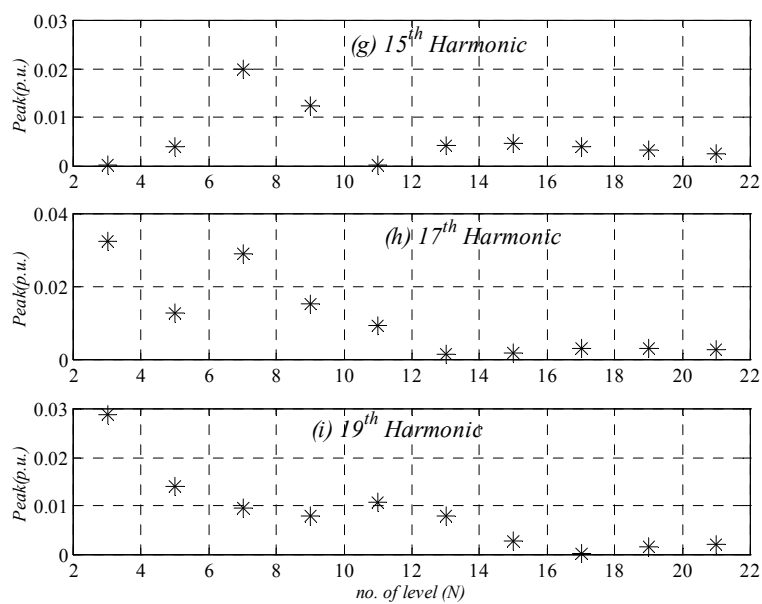

Figure 9. Variation of lower order harmonics $\left(15^{\text {th }}, 17^{\text {th }}\right.$ and $\left.19^{\text {th }}\right)$ with respect to $N(1$ p.u. $=326 \mathrm{~V})$

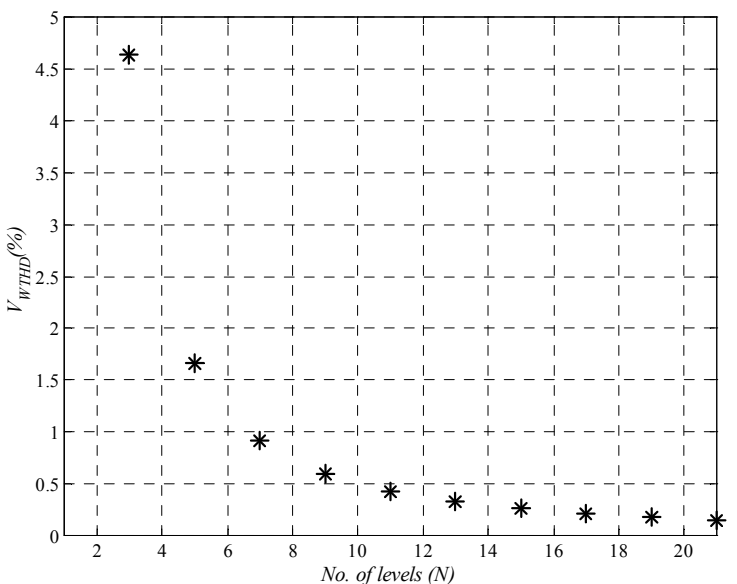

Figure 10. Variation of $V_{W T H D}$ with respect to $N$

at fundamental frequency switching with step modulation [2][4].

In order to study the harmonics and the THD of the output voltage and load current, multilevel inverters with $N$ (where $N$ is odd) varying from 3 to 21 are simulated using MATLABSIMULINK toolbox. Step modulation with fundamental frequency switching is employed. Single-phase 2KVA R-L load with 0.8 power factor is assumed. The output waveforms of three-level and seven-level inverter are shown in fig. 4 and fig. 5 respectively.

A large number of samples per cycle are taken and from these sampled data, the harmonic components are computed using FFT function of MATLAB. The harmonic spectra of output waveforms of three-level and seven-level inverter are shown in fig. 6 and fig.7 respectively. Step modulation preserves half wave symmetry; hence the even harmonics are absent from the output waveforms. The lower order harmonics will have adverse effects in the load. The variations of lower order harmonics (5th, 7th, 9th, 11th, 13th, 15th 17th and 19th) with the number of level $N$ are plotted in fig. 8 and fig.9. From these plots it can be observed that these lower order harmonics
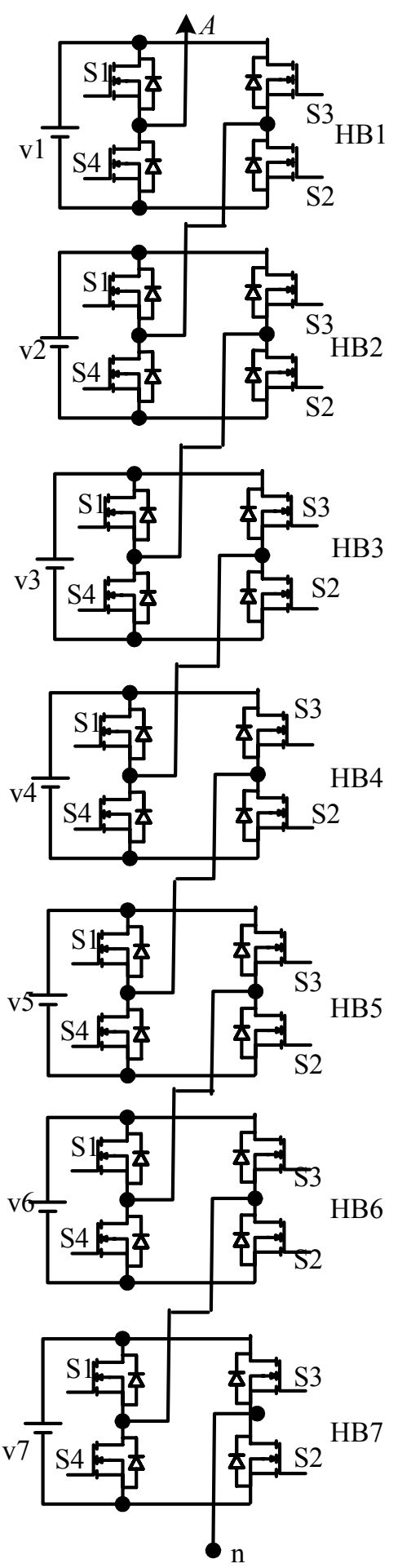

Figure 11. Power Circuit of fifteen level cascaded $\mathrm{H}$-bridge inverter

are significantly small for $N>11$. The weighted $T H D$ of the phase voltage, $V_{W T H D}$, defined in (1), can be taken as a measure of waveform quality. In (1), $V_{l}$ is the rms value of the fundamental, $h$ is the harmonic order and $V_{h}$ is the rms value of the $h^{\text {th }}$ harmonic component. 


$$
V_{W T H D}=\frac{\sqrt{\sum\left(v_{h} / h\right)^{2}}}{V_{1}}
$$

From the FFT data the $V_{\text {WTHD }}$ of the phase voltage is computed using (1). The variation of $V_{\text {WTHD }}$ with respect to $N$ is shown in fig. 10. It can be observed that $V_{W T H D}$ is less than $0.5 \%$ for $N>11$.

\section{Simulation Results}

From the above simulation results it is seen the $\mathrm{N}>11$ will result in $T H D$ less than $0.5 \%$. Taking into consideration the voltage levels of the photovoltaic cell and the storage batteries of the proposed system, a fifteen level-cascaded H-Bridge inverter is proposed. The power circuit of the proposed fifteen level cascaded H-Bridge inverter is shown in Fig. 11. The dc voltage of each of the H-Bridge cells is set at 48 Volts and the peak output voltage is 325 volts. The proposed fifteen-level inverter is simulated in MATLAB-SIMULINK toolbox. A single-phase, 2KVA, R-L load of 0.866 power factor is assumed. The simulation results of phase voltage and the load
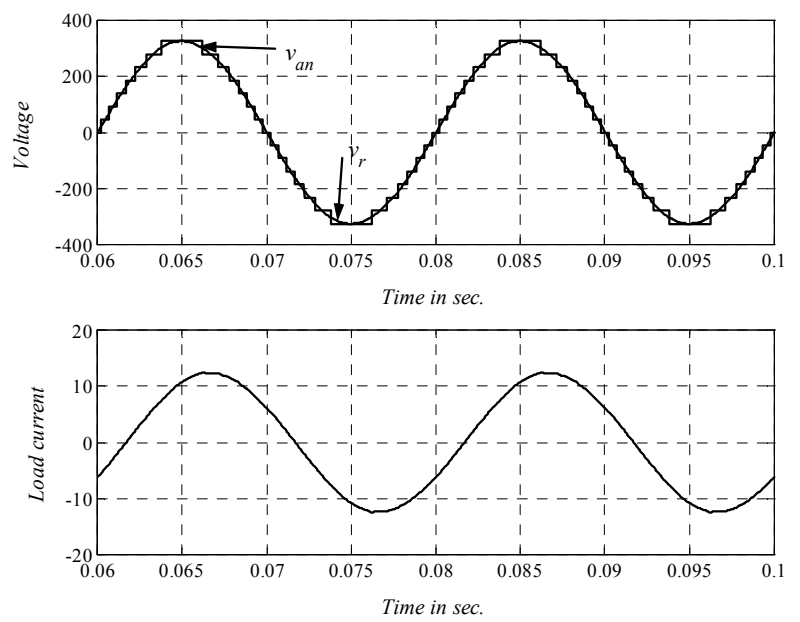

Figure 12. Simulation results: Phase voltage and load current of fifteenlevel cascaded H-Bridge inverter
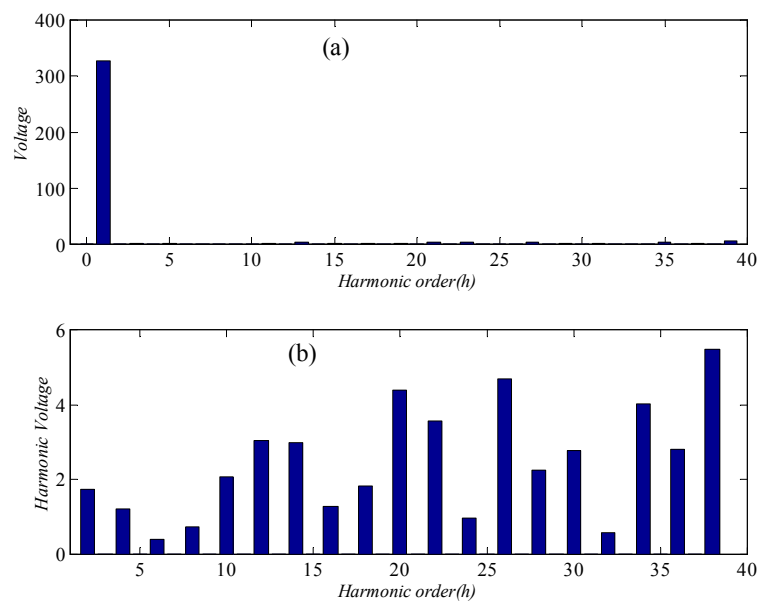

Figure 13. Harmonic spectra of phase voltage (peak value) of fifteen level cascaded H-Bridge inverter (a) Fundamental and harmonics (b) Only harmonic components current are shown in fig. 12. The harmonic spectra of the phase voltage and load current are given in fig. 13(a) and fig 14(a) respectively. Compared to fundamental component, the magnitude of the harmonics is very low; hence only harmonic components of the phase voltage and load current are shown in fig. 13(b) and fig 14(b) respectively.

\section{EXPERIEMNTAL SETUP}

A 2KVA single-phase photovoltaic power supply unit is designed and its implementation is under progress. The distribution system in INDIA is three-phase four wire 415 Volts, $50 \mathrm{~Hz}$ ac supply. Bulk of the domestic loads operates from single phase $230 \mathrm{~V}, 50 \mathrm{hz}$ ac system. So the output voltage of the proposed power supply is designed for 230 Volts ac supply. The peak output voltage of the inverter is 325 volts. For a fifteen-level inverter, seven $\mathrm{H}$-Bridge cells are connected in cascade. The dc bus voltage of individual H-Bridge cells is 48 volts.

Fig. 15 shows the arrangement of photovoltaic cells and storage batteries for single $\mathrm{H}$-Bridge cell. Each photovoltaic cell has a rated power of $100 \mathrm{~W}$ with voltage variation of 16 to 21 volts (nominal $18 \mathrm{~V}$ ) depending on the operating conditions such as light intensity, etc. Three photovoltaic cells are connected in series to get a nominal voltage of 54volts. Two numbers of $24 \mathrm{volts}$ battery packs are connected in series to get a nominal dc bus of 48 volts. These batteries are charged from the photovoltaic unit through a controlled charging circuit. The photovoltaic grid voltage and the battery voltage of commercially available photovoltaic power supply units are also 54 Volts and 48 volts respectively.

There are seven identical units (HB1 to HB7) in the proposed photovoltaic supply system with an installed power generating capacity of 2100 Watts from a total of 21 photovoltaic panels. The photovoltaic panels are mounted such that the panels receive maximum solar energy for most part of the day. Since the capacity of the proposed unit is low, photovoltaic panels are mounted on a fixed structure and no maximum power tracking methods are employed. However the mounting structure has arrangement to alter the orientation of panels manually during winter solstice and summer solstice. In
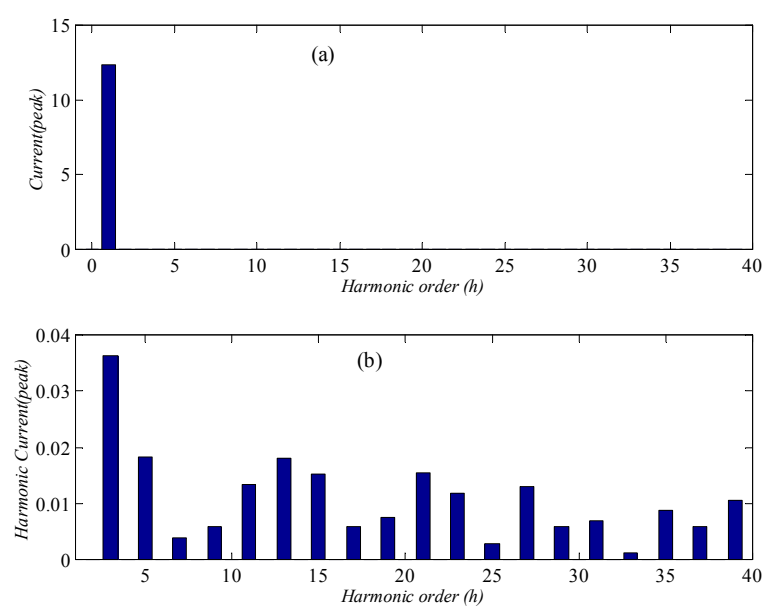

Figure 14. Harmonic spectra of load current of fifteen -level cascaded HBridge inverter (a) Fundamental and harmonics (b) Only harmonic components 


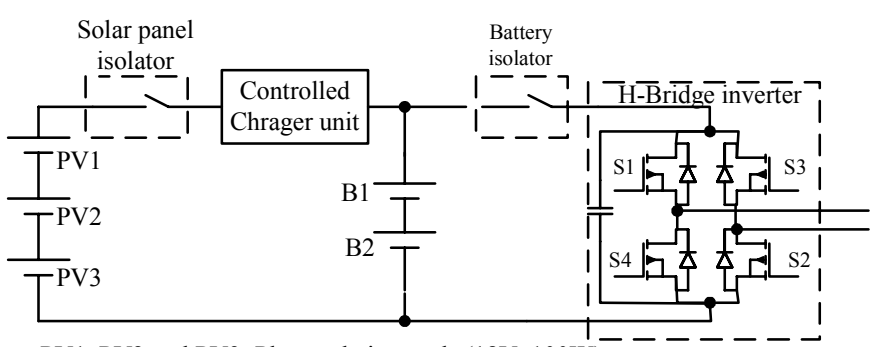

PV1, PV2 and PV3: Photovoltaic panels (18V, 100W) B1, B2: Storage cells (24V)

Figure 15 : Block diagram of a single H-Bridge unit
- The magnitude of the lower order harmonics is very low. Hence there is no need of filter circuit.

- The power circuit is designed to have modular structure. All the H-Bridge units are identical. So replacing the faulty units will be easy and quick. The downtime can be reduced and hence the reliability of the system can be improved.

- During faulty conditions, the faulty H-Bridge unit can be bypassed and taken out for maintenance and the inverter can still be used with reduced power rating. Hence power interruption can be reduced.

- Step modulation technique is employed. One of the
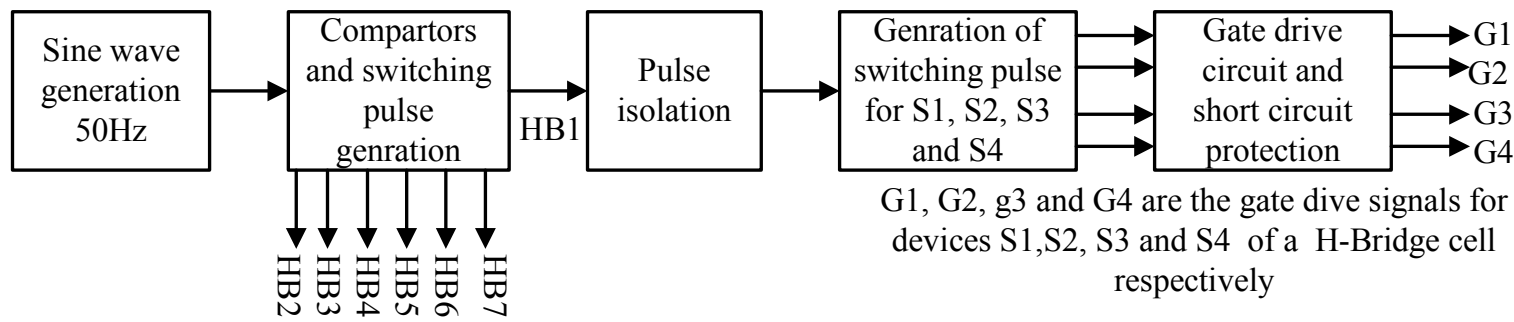

Figure 16. Functional block diagram the gating signal and protection circuit.

this arrangement, the photovoltaic panels generate rated power at rated voltage from morning $9.00 \mathrm{am}$ to $4.30 \mathrm{pm}$ in the afternoon. From 7.30 am to 9 am and $4.30 \mathrm{pm}$ to $6.00 \mathrm{pm}$, the photovoltaic cells generate $80 \%$ to $90 \%$ of the rated energy.

\section{A. Gating signals and device protection}

The functional block diagram of the gating signal generation and the gate drive for single H-Bridge cell is shown in fig 16. Sinusoidal reference signal is compare with seven discrete voltage levels to generate the gating signals for seven $\mathrm{H}$-Bridge units. These gating signals for $\mathrm{HB} 1$ to $\mathrm{HB} 7$ are shown in fig. 17. Since the dc bus of the H-Bridge cells are isolated each other these gating signals are to be isolated. In each of the H-Bridge unit, four isolated gate signals for devices S1, S2, S3 and S4 are generated from these gate signals. Each of the devices of the H-Bridge is protected against short-circuit in the gate drive cards. Under fault conditions, the isolators will isolate the battery and photovoltaic units. This arrangement will make each of the H-Bridge unit is independent and identical. So modular structure is maintained. This will help in replacing the faulty units and reducing the down time of the inverter. Under fault conditions, the faulty unit can be bypassed and the inverter can still be used with reduced power capacity.

\section{DISCUSSION AND CONCLUSIONS}

A fifteen-level cascaded H-Bridge based power supply unit is proposed. The simulation results are presented. The proposed configurations have several attractive features.

- The output voltage is compatible with the load. Hence output transformer is not needed.

- Output voltage has fifteen-level and the wave shape is near sinusoidal. The $V_{\text {WTHD }}$ of the output voltage is $0.26 \%$.

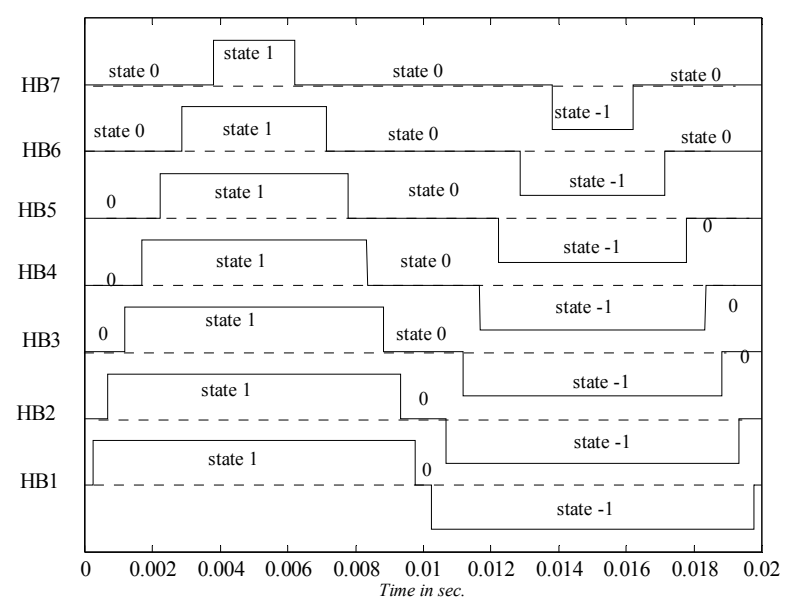

Figure 17. Gating signals for all the H-Bridges

drawbacks of this modulation method is, the duty cycle of the H-Bridges is not uniform. The H-Bridge units with larger duty cycle will share more power and the H-Bridge units with low duty cycle will be under utilized. In the proposed configuration the photovoltaic unit associated with HB1 will be overloaded and the load sharing will reduce from HB1 to HB7. This problem can be overcome by rotating the gating signal over every half cycle [2] or over every cycle [4]. However this requires additional circuit in the gate drive circuit. Alternatively the problem of non-uniform loading can be addressed by grading the rating of the photovoltaic sources of each unit according to their loading. Adding additional photovoltaic panels in parallel and increasing the storage capacity of the batteries can increase the capacity of the units, which have larger duty cycle. 
- In the proposed configuration, equal dc voltages are selected for each of the units. However different voltage levels can be used to generate required voltage output and this will also give freedom to eliminate some of the harmonics.

- $\quad$ The gating angle $\theta$ can be selected to eliminate some of the harmonics completely. However this method will be useful for low values of $N$. Generation of sinusoidal reference signal, cyclic rotation of the gating signals and selection of gating signal to eliminate the harmonics can be incorporated in a digital circuit and performance of the inverter can further be improved.

- Modular structure will help in duplicating each unit. Hence for higher power rating a three phase cascaded $\mathrm{H}$-Bridge can be realized.

\section{REFERENCES}

[1] Jih-Sheng Lai and Fang Zheng Peng, "Multilevel converters - A new breed of power converters,"IEEE Trans. on Industry Applications, vol. 32, No.3, May/June 1996, pp. 509-517.
[2] G. Leon M.Tolbert and Fang Z.Peng, " Mulitlevel converter as a utility interface for renewable energy ssytems," in proceedings of the IEEE Power Engineering Society summer meeting, 2000, vol.2, 16-20, July 2000, pp. 1271-1274.

[3] D.A.Rendusara, Cengelce, Prasad N. Enjeti, V. R. Stefanovic and J.WGray, "Analysis of common mode voltage -"nuetral shift" in medium voltage PWM adjustable speed drive system," IEEE Trans. Power Electronics, vol.15 No.6, pp1124-1133, Nov. 2000

[4] Nikolaus P.Schilibi, Tung Nguyen and Alfred C. Rufe, "A three phase multilevel converter for high power induction motors, " IEEE Trans. on Power Electronics, vol. 13, No. 5, Sept. 1998, pp. 978-986.

[5] Brian A. Welcho, M.B.R. Correa and Thomas A.Lipo, "A three level MOSFET inverter for low power drives," in IEEE trans. on Industrial Electronics, vol. 51, no.3, June 2004, pp. 669-674.

[6] Keith A. Corzine, Mike W. Wielebski, Fang Z. Peng and Jin Wang, "Control of cascaded mulilevel inverters" , IEEE Trans. on Power Electronics, vol. 19, no. 3, may 2004, pp.732-738.

[7] M.S.Imamura and W.Palz, " Photovoltaic system technology - A European system handbook, H.S. stephens and Associates, ISBN 09510271-9-0, 1992.

[8] G.Carrara, S.Gardalla, M. Marchesoni, R Salutari and G. Sciutto, “ A new multilevel PWM method: A theoritical analysis", IEEE Tran. On Power Electronics, vol.7, no.5, July 1992, pp 497-505. 